\title{
Adoption of Virtual Reality in Construction Projects
}

\author{
P. Selvaprasanth ${ }^{1}$ T. Karthigaipriya ${ }^{2}$ J. John $^{3}$ \\ ${ }^{1,2}$ Assistant Professor, ${ }^{3} \mathrm{PG}$ Student \\ Department of Civil Engineering, \\ Thiagarajar College of Engineering, Madurai, 625015 \\ Tamil Nadu, India \\ *selvatamil50@gmail.com \\ tkpcivil@gmail.com
}




\begin{abstract}
In recent years, virtual reality has emerged in various fields such as manufacturing sectors, construction sectors etc. Virtual reality technology has a wide variety of applications in various fields. Several applications of VR in construction sector are design review and support, construction support, operations and management, safety training, stakeholder management. Recent researches had shown that VR can also be used widely in decision making process. Despite the various applications of VR in construction sectors, the adoption level of the VR technology is comparatively very low. This study aims to identify the factors that are preventing the adoption of virtual reality in construction projects. The factors are identified through a wide review of literature survey and analysed by means of questionnaire survey with statistical methods. The factors are ranked through the analysis and the most affecting factors are found out. The findings of this study show that requirements of specialized high processing equipment, high investment in VR, lack of awareness about the technology, lack of client's interest, limited finance of the organizations, existence of champions using VR are the most preventing factors for the adoption of VR in construction projects. To mitigate these issues, several possible mitigation measures has been suggested in this study.
\end{abstract}

Key words: virtual reality, construction, preventing factors, adoption, limiting, digitized construction

\title{
1.INTRODUCTION
}

In a construction, the project is a structured and sequential way having number of activities taking place at different time and space in which the design specifications of the final product are communicated through 2D drawings and written document in the old times. In such cases there was a large margin of errors and deviations from the design to the product. As the computers and other hardware become popular, then came the computerized $2 \mathrm{D}$ drawings and then the 3D BIM models for the designing phase of the project. These technologies helped to reduce the margin of errors and deviations from the design to the final product. As the technologies get evolved the construction industries had tried to adopt the appropriate tools and technologies and make its full potential use in the field of construction throughout the life cycle of the project. Now in the modernized world the technologies are evolving with advanced hardware, Information and Communication Technologies (ICT), the construction industries should make efforts to learn and grasp the potential technologies which can be applied in constructions. One such technology is virtual reality (VR) which has 
a wide variety of applications in various fields. VR has been defined as a way for humans to visualize, manipulate and interact with computers and extremely complex data .[1] Virtual reality (VR) is an emerging technology in various fields and it had laid a strong foundation in the field of entertainment such as gaming. And it continues to emerges in various fields like construction, manufacturing etc. The aim of this study is to investigate the factors that are preventing the adoption of virtual reality in construction projects and to suggest possible measures to mitigate these factors.

Since the early 90's, VR has matured considerably, and has begun to offer many powerful solutions to very difficult problems. [2] Virtual reality is one of advanced form of computer technology to create a stimulated environment which is commonly known as virtual environment (VE). A virtual reality interface places the user inside the virtual environment and enables the users to get immersed and interact with the 3D objects in the virtual environment. These virtual environments can be as real as possible with the stimulated senses such as vision, hearing and touch. The following are the requirements for a VR setup

1. High resolution display

2. High end processing unit with high graphics

3. VR headsets

4. Audio system

5. 3D modelling software

6. VR stimulation software

7. Sensory devices

With the above-mentioned required components, a VR can be set up and a virtual environment can be stimulated for virtual experience.

VR presents a variety of new possibilities across a wide spectrum of industries [3]. In recent years, virtual reality (VR) is being used in the construction sectors in various countries around the world. Professionals had always used tools to help them visualize the final product at the initial stage for better understanding and quality of the product. First it was with 2D drawings in paper and documents, then with the advancement of computers and technologies the professionals are using computerized 3D models and BIM models for better understanding the design. Yet still there are few margins of errors and deviation of the product from the design. Virtual reality offers to get the user into the model and look at every corner of the design even before the foundation is laid. That would help the professionals to know the design in a better way than 3D models and the final product can be built without any deviations from the design. According the use cases and researchers, virtual reality have 
a wide variety of applications in constructions field such as design support and review, construction support, operations and management, safety trainings etc. There are several researches with case studies to support that virtual reality can be greatly used in decision making process. Therefore, with further researches the adoption of virtual reality in construction can be made easier and the organizations may consider the adoption of the technology with its benefits and applications in the construction sector.

\section{LITERATURE REVIEW}

[4] studied the barriers that are affecting the adoption of virtual reality in the UK constructions firms in the public sector. In his paper he made a three-phase factor analysis method to determine the critical factors that are affecting the implementation of the technology. The first phase is the determination phase in which he identifies the factors through pervious literatures, followed by data collection through questionnaire survey which was the second phase and the final phase was the analysis of the data. He used discriminant and empirical analysis for the study and found six factors that are most affecting the adoption of the technology in the firms. [5] examined the acceptance and adoption of virtual reality by the people in construction industry. He identified the factors that are preventing the adoption of the technology. He made a qualitative analysis through face-to-face interview in a semi structured way along with a VR program among the university students and academia staff. He created a VR stimulation for the participants and they were allowed to use it followed by the face-to-face interview. The author collected, interpreted and made the suggestions for the qualitative analysis at the same time for the responses he got from the participants. In this paper he had also proposed several solutions for overcoming the factors that are affecting the adoption of the VR in the construction industry. [6] studied the driving and limiting factors of both augmented and virtual reality in construction. He employed a mixed research method with both qualitative and quantitative analysis. In qualitative analysis, he conducted face to face focus group discussions with experts to identify the driving and limiting factors of the two technologies. And in quantitative analysis he used reliability analysis and multi-variate analysis of covariance to prioritize the most affecting factors. He identified a total of 42 factors (both limiting and driving) and categorized them. A road map was also proposed in the study for the short term \& medium term overcome of these factors for a wide adoption of the technologies in construction. [2] examined and reviewed in detail about what virtual reality is, its requirements such as hardware, software. He had also reviewed the successful implementation of virtual reality in some of the construction projects and briefed its 
applications in the field such as house building, construction safety and training, project planning and monitoring, site layout planning, analysing tool and architectural walkthrough. [7] studied the industrial trend in adopting the augmented and virtual reality technologies in architecture, engineering, construction industries. For this, he conducted two rounds of survey at two different period of time (a year apart) among the industrial experts and researchers. Unpaired t-test had been used in this study to analyse the responses from the survey. The findings of this paper states that there is a significant increase in the use of augmented and virtual reality in the industries between the time period of the study and also it states that the experts are anticipating a solid growth in the adoption of these technologies in the next 5-10 years. [8] studied the usage of augmented and virtual reality in architecture, engineering, construction industries and proposed a research agenda for the gaps in adoption of these technologies. For this, workshops and questionnaires were conducted among the experts and academia staff. Through this paper, the author provides required information to the industries for adoption decisions and provides a roadmap for the researchers for future works by categorizing the existing usage of augmented and virtual reality in the construction industries. [9] in his thesis investigated how virtual reality can be used during various stages of constructions such as planning, designing and realization phases. He also investigated its benefits and how a construction industry can make use of the potential benefits of virtual reality. He used a digital prototype of virtual reality for visualizing to make it easier to identify, analyse and communicate the design in order to have a better and improved decision making. He also made both qualitative and quantitative investigation of two case studies in different phases of a project. This paper concludes that virtual reality can increase the efficiency of designing and planning phase which will increase the quality of final product and a better financial result. [10] studied the evaluation of virtual reality technology in an engineering design review process. The technology was checked for its usability and user experience and then evaluated in a real, authenticated design review in an industrial environment. A prototype was built in virtual environment same as 3D CAD design and the participants were asked to find out the flaws in the design and a survey was conducted for the quantitative analysis. This paper concludes that VR supported review enabled the participants to see slightly more flaws than in CAD supported review. And also, VR provides more useful addition to the industries.

The various factors that are preventing the adoption of VR have been studied in detail and knowledge was gained. The methods to analyse the factors have been studied. Since papers from various countries have been studied, it gives a vast idea about the topic of the 
study. Virtual reality is one of the emerging technologies in the modern world with a wide variety of applications, its adoption in construction industries may have significantly changes in this sector.

\section{METHODOLOGY}

This chapter explains the methodology of the study undertaken and the fig. 1 shows the proposed methodology of the research. A detailed survey of literature was done to gain the knowledge and details about the study.

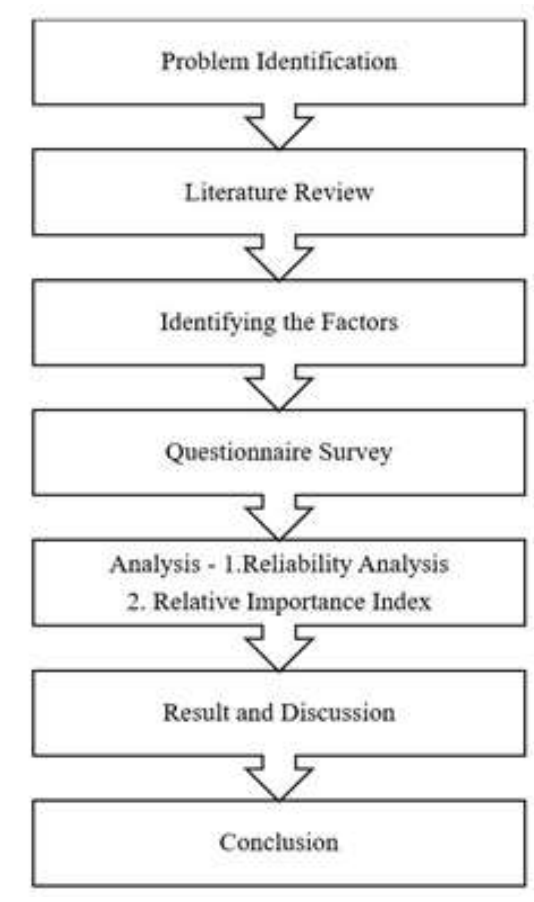

Fig. 1. Methodology

\section{Data Collection}

The data required for this study are the factors preventing the adoption of virtual reality and obtaining responses from field experts through questionnaire survey.

1) Identifying the factors that are preventing the adoption: The factors that are preventing the adoption of VR in construction projects are identified from previous research works of researchers such as [4],[8] through a wide survey of literature. Table I shows the identified factors which are preventing the adoption of VR in construction projects. 
Table 1 Factors Preventing the Adoption

\begin{tabular}{|l|l|}
\hline S1. No & $\begin{array}{l}\text { Factors Preventing the Adoption of Virtual Reality in } \\
\text { Construction Projects }\end{array}$ \\
\hline 1 & High investment in VR \\
\hline 2 & Shortage of skills \\
\hline 3 & Lack of expertise knowledge \\
\hline 4 & Unwilling to adopt new technology \\
\hline 5 & Non-user friendly \\
\hline 6 & Difficulties in multi user capabilities \\
\hline 7 & $\begin{array}{l}\text { Requirement of specialized high-end processing } \\
\text { equipment }\end{array}$ \\
\hline 8 & Limited Finance \\
\hline 9 & Expensive training programs \\
\hline 10 & Lack of client's interest \\
\hline 11 & Top management support \\
\hline 12 & Inadequate marketing of the technology \\
\hline 13 & Lack of time to explore the technology \\
\hline 14 & Lack of awareness about the technology \\
\hline 15 & Existence of champions using the technology \\
\hline
\end{tabular}

2) Questionnaire Survey: A questionnaire survey was prepared for the study to analyse the critical factors that are preventing the adoption of VR in construction projects. The questionnaire was prepared using google forms and circulated among the targeted audience. The survey was targeted to civil engineers, architects and consultants. A total of 47 respondents were obtained from the survey and their responses were recorded. The respondents were asked to give the impact of the factors from $1-5$ in the 5-point Likert scale were,

1. 1 denotes Very low impact

2. 2 denotes Low impact

3. 3 denotes No impact

4. 4 denotes High impact

5. 5 denotes Very high impact.

3) Responses from questionnaire survey: The following were responses obtained from the 47 respondents for the above given questionnaire survey. The responses for the personal details are as follows:

Fig. 2 shows the experiences of the respondents in the construction field. This pie chart shows that $25.5 \%$ of the total respondents have greater than 5 years of experience, $25.5 \%$ of the respondents have 3-5 years of experience, $38.3 \%$ of the respondents have 1 - 
3 years of experience and $10.6 \%$ of the respondents have less than 1 year of experience in their respective designations in construction field

Years of experience

47 responses

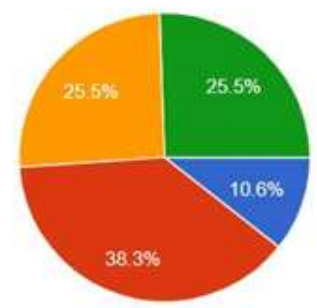

- Less than 1 year

- 1.3 Years

3.5 Years

- Greater than 5 Years

Fig. 2. Years of experience in construction field

Fig. 3 shows how many of the respondents have used or tried VR before either in construction field or other fields like entertainment. This pie chart represents that $53.2 \%$ of the respondents had never tried VR before in any of its application and $46.8 \%$ of respondents had used VR.

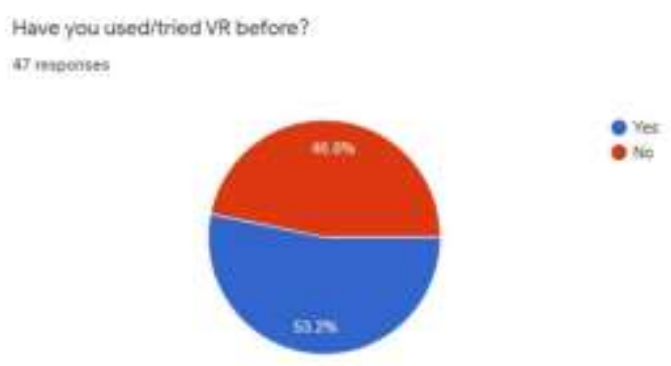

Fig. 3. Whether they have used or tried VR before?

Fig. 4 represents the years of experience of the respondents who have used VR in construction field. $61.7 \%$ of the respondents don't have any prior experience using VR in construction, $14.9 \%$ of the respondents have less than 1 year experience, $10.6 \%$ of the respondents have 1-3 years of experience, $4.3 \%$ of the respondents have 3-5 years of experience and $8.5 \%$ of the respondents have more than 5 years of experience in using VR in construction field.

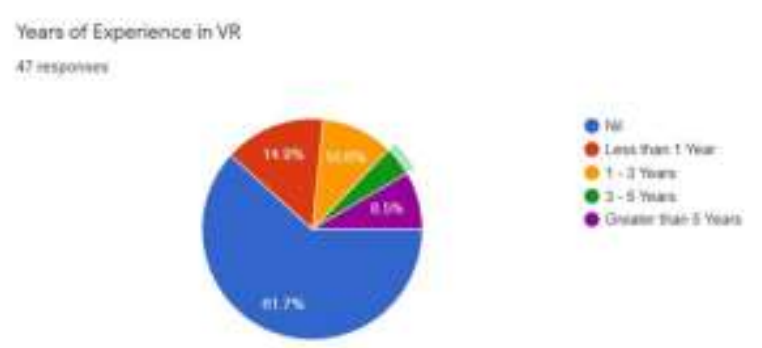

Fig. 4. Years of experience in VR 
Fig. 5 shows the responses i.e., the impact of the identified factors in adoption of VR in construction project given by the above recorded 47 respondents are as follows:

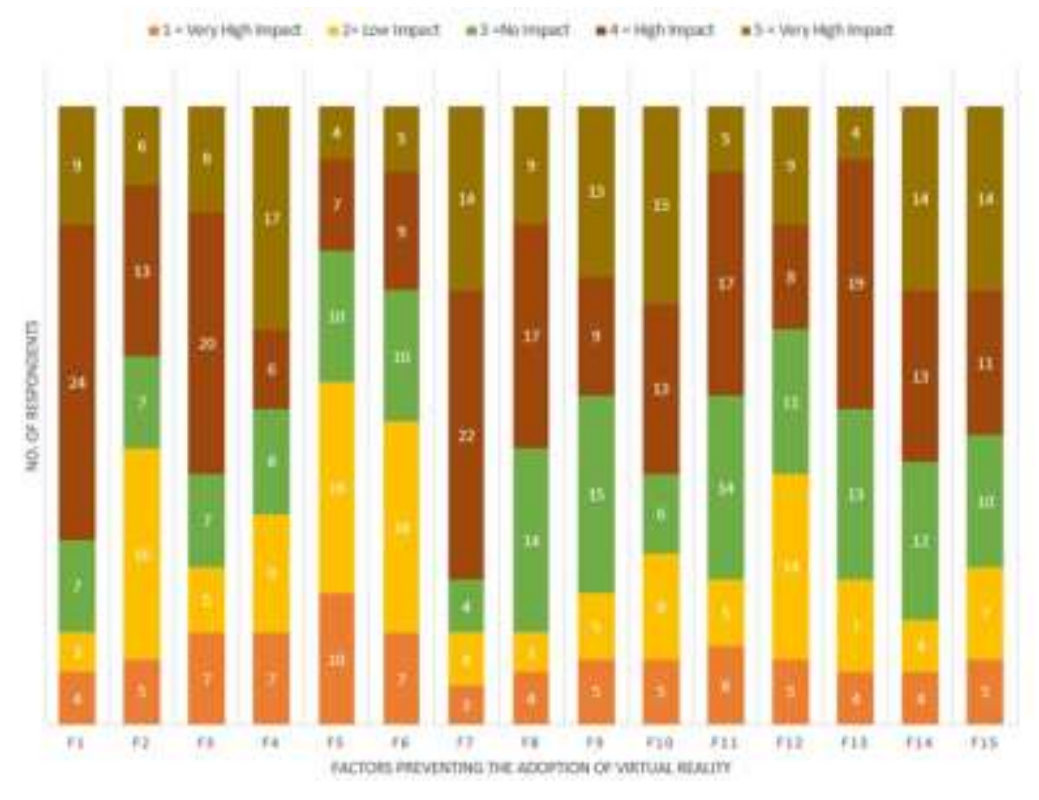

Fig. 5. The responses recorded in the questionnaire survey

\section{Analysis}

The above recorded responses from the respondents through questionnaire survey is subjected to two different types of quantitative analysis. Both the analyses are done in Microsoft Excel software. The two analyses chosen for this study are:

1. Reliability Analysis (Internal consistency)

2. Relative Importance Index (RII)

1) Reliability Analysis: Reliability is the measure of overall consistency. A measure is said to be reliable when it produces similar results under same conditions. There are various kinds of reliability coefficients with the values ranging from $0-1$ where 0 represents many errors and 1 represents no error. There are several classes of reliability analysis such as

1. Inter-rated reliability

2. Test-retest reliability

3. Inter-method reliability

4. Internal consistency

From the above-mentioned classes, the internal consistency is chosen for this study. It assesses the consistency of the results within a test. The internal consistency is usually 
measured using Cronbach's alpha $(\alpha)$. The formula for the Cronbach's alpha and the thumb rule for the values of the alpha are given below.

$$
\alpha=\left(\frac{\mathrm{k}}{\mathrm{k}-1}\right)\left(1-\frac{\sum_{\mathrm{i}=1}^{\mathrm{k}} \sigma_{\mathrm{y}_{\mathrm{i}}}^{2}}{\sigma_{\mathrm{x}}^{2}}\right)
$$

Where,

$\alpha$-Cronbach's alpha

$\mathrm{k}$ - number of items in the test i.e., number of factors

$\sigma_{\mathrm{y}_{\mathrm{i}}}^{2}$ - variances associated with the factors

$\sigma_{\mathrm{x}}^{2}-$ Variances associated with total scores

Table II shows the thumb rule for the values of the Cronbach's alpha

TABLE II THUMB RULE FOR INTERNAL CONSISTENCY

\begin{tabular}{|l|l|}
\hline Cronbach's Alpha & Internal Consistency \\
\hline $0.9 \leq \alpha$ & Excellent \\
\hline $0.8 \leq \alpha \leq 0.9$ & Good \\
\hline $0.7 \leq \alpha \leq 0.8$ & Acceptable \\
\hline $0.6 \leq \alpha \leq 0.7$ & Questionable \\
\hline $0.5 \leq \alpha \leq 0.6$ & Poor \\
\hline$\alpha \leq 0.5$ & Unacceptable \\
\hline
\end{tabular}

2) Relative Importance Index (RII): Relative Importance Index (RII) is one of the most commonly used analysis to rank or prioritize the items in a test for Likert scale type questionnaire survey. RII is an appropriate tool to identify the important criteria based on participants replies and it ranks the items within a test using its relative importance. RII is chosen for this study to rank the factors according to their relative importance. The formula for calculating the RII is give below.

$$
\begin{gathered}
\text { RII }=\frac{\Sigma W}{A * N} \\
\Sigma W=1 n_{1}+2 n_{2}+3 n_{3}+4 n_{4}+5 n_{5}
\end{gathered}
$$

Where,

RII - Relative Importance Index

W - Weightage given to each factor by the respondents

A - Highest weight i.e., 5 in this study

$\mathrm{N}$ - Total number of respondents i.e., 47 in this study 

$\mathrm{n}_{1}$ - Number of respondents for 1 in the Likert scale
$\mathrm{n}_{2}$ - Number of respondents for 2 in the Likert scale
$\mathrm{n}_{3}$ - Number of respondents for 3 in the Likert scale
$\mathrm{n}_{4}$ - Number of respondents for 4 in the Likert scale
$\mathrm{n}_{5}$ - Number of respondents for 5 in the Likert scale.

\section{RESULT AND DISCUSSION}

The recorded responses from the 47 individual respondents are fed into excel software for the two chosen analyses for the study. The results from the performed analyses are given below.

\section{Reliability Analysis}

Responses of the questionnaire survey fed into excel software for the analysis and it is show in the below figure. The mean, variance, standard deviation (S.D) is calculated for each factor to determine the sum of variances. The total of the scores for every single response is calculated for the variance of the total scores. Fig. 6. shows the calculation of the Cronbach's alpha using MS Excel software.

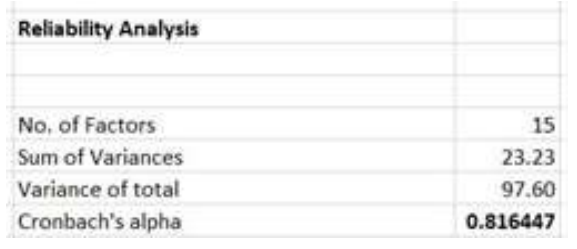

Fig. 6. Calculation of Cronbach's alpha

The obtained value of Cronbach's alpha is 0.816447 which is approximately equals to 0.82. According to the thumb rule of internal consistency, when the value is $0.8 \leq \alpha \leq 0.9$, the consistency of the test is said to be good. Therefore, the responses from this survey are said to be good, internally consistent and reliable to take further steps of the study.

\section{Relative Importance Index (RII)}

To calculate the RII for the factors the responses were fed into excel software and the frequency of each weight of the 5-point Likert scale for all the 15 factors were determined first and the total number of respondents is noted. Then frequency is multiplied with its corresponding coefficient from the formula for each factor and then the total is calculated. The calculations from the excel sheet is show below. Fig. 7. shows the frequency of the weights for each factor, the total of frequencies when multiplied with their corresponding coefficients from the formula, total number of respondents and the calculation of the RII. Fig. 8. shows the ranks of each factor according to their relative importance. 


\begin{tabular}{|c|c|c|c|c|c|c|c|c|c|c|c|c|c|c|c|}
\hline \multicolumn{16}{|c|}{ Frequency } \\
\hline & $F 1$ & $\sqrt{2}$ & $\mathrm{FB}$ & $F 4$ & F5 & F6 & $F 7$ & $\mathrm{Fg}$ & F9 & F10 & F11 & $F 12$ & $F_{13}$ & 514 & F15 \\
\hline 1 & 4 & 5 & 7 & 7 & 10 & 7 & 3 & 4 & 5 & 5 & 6 & 5 & 4 & 4 & 5 \\
\hline 2 & 3 & 16 & 5 & 9 & 16 & 16 & 4 & 3 & 5 & 8 & 3 & 14 & 7 & 4 & 7 \\
\hline 3 & 7 & 7 & 7 & 8 & 10 & 10 & 4 & 14 & 15 & 6 & 14 & 11 & 13 & 12 & 10 \\
\hline 4 & 24 & 13 & 20 & 6 & 7 & 9 & 22 & 17 & 9 & 13 & 17 & 8 & 19 & 13 & 11 \\
\hline 5 & 9 & 6 & 8 & 17 & 4 & 5 & 14 & 9 & 13 & 15 & 5 & 9 & 4 & 14 & 14 \\
\hline Total & 4) & 47 & 47 & 47 & 47 & 47 & 47 & 47 & 47 & 47 & 4) & 47 & 47 & 47 & 47 \\
\hline \multicolumn{16}{|l|}{ RII } \\
\hline & $f 1$ & $F_{2}$ & $F_{3}$ & $F_{4}$ & FS & F6 & F7 & $F 8$ & F9 & $F 10$ & $F 11$ & $F 12$ & F13 & $F 14$ & F15 \\
\hline 1 & 4 & 5 & 7 & 7 & 10 & , & 3 & 4 & 5 & 5 & 6 & 5 & 4 & 4 & 5 \\
\hline 2 & 6 & 32 & 10 & 18 & 32 & 32 & 8 & 6 & 10 & 16 & 10 & 28 & 14 & 8 & 14 \\
\hline 3 & 21 & 21 & 21 & 24 & 30 & $\begin{array}{l}32 \\
30\end{array}$ & 12 & 42 & 45 & 18 & 42 & 33 & 39 & 36 & 30 \\
\hline 4 & $\begin{array}{l}21 \\
96\end{array}$ & $\begin{array}{l}21 \\
52\end{array}$ & 80 & 24 & $\begin{array}{l}30 \\
28\end{array}$ & $\begin{array}{l}30 \\
36\end{array}$ & $\begin{array}{l}12 \\
88\end{array}$ & 68 & 36 & $\begin{array}{l}188 \\
52\end{array}$ & 68 & 32 & $\begin{array}{l}39 \\
76\end{array}$ & $\begin{array}{l}56 \\
52\end{array}$ & ${ }_{44}$ \\
\hline 5 & 45 & 30 & 40 & 85 & 20 & 25 & 70 & 45 & 65 & 75 & 25 & 45 & 20 & 70 & 70 \\
\hline Total & 172 & 100 & 158 & 158 & 120 & 130 & 181 & 165 & 161 & 166 & 151 & $\begin{array}{l}463 \\
143\end{array}$ & $\begin{array}{l}20 \\
153\end{array}$ & 170 & 163 \\
\hline Total N & 47 & 47 & 47 & 47 & 47 & 47 & 47 & 47 & 47 & 47 & 47 & 47 & 47 & 47 & 47 \\
\hline$A^{*} N$ & 235 & 235 & 235 & 235 & 235 & 235 & 235 & 235 & 235 & 235 & 235 & 235 & 235 & 235 & 235 \\
\hline REII & 0.73 & 0.60 & 0.67 & 0.67 & 0.51 & 0.55 & 0.77 & 0.70 & 0.69 & 0.71 & 0.64 & 0.61 & 0.65 & 0.72 & 0.69 \\
\hline Rank & 2 & 13 & 8 & 8 & 15 & 14 & 1 & 5 & 7 & 4 & 11 & 12 & 10 & 3 & 6 \\
\hline
\end{tabular}

Fig. 7. Frequency and RII calculations

\begin{tabular}{|c|c|}
\hline Rank & Factors \\
\hline 1 & $\begin{array}{c}\text { Requirement of specialized high processing } \\
\text { equipment }\end{array}$ \\
\hline 2 & High investment in VR \\
\hline 3 & Lack of awareness about the technology \\
\hline 4 & Lack of client's interests \\
\hline 5 & $\begin{array}{c}\text { Limited Finance of the construction } \\
\text { organization }\end{array}$ \\
\hline 6 & Existence of champions using the technology \\
\hline 7 & Expensive training programs \\
\hline 8 & Lack of expertise knowledge \\
\hline 8 & Unwillingness to adopt new technology \\
\hline 10 & Lack of time to explore the technology \\
\hline 11 & $\begin{array}{c}\text { Top management support of the construction } \\
\text { organization }\end{array}$ \\
\hline 12 & Inadequate marketing of the technology \\
\hline 13 & Shortage of skilled persons in VR \\
\hline 14 & Difficulties in multi user capabilities \\
\hline 15 & Non - user friendiv \\
\hline
\end{tabular}

Fig. 8. Ranking of

factors.

\begin{tabular}{|c|c|c|}
\hline F.No & Factors & Rank \\
\hline 1 & High Investment in VR & 2 \\
\hline 2 & Shortage of sikilled persons in VR & 13 \\
\hline 3 & Lack of expertise knowledge & 8 \\
\hline 4 & Unwillingness to adopt new technology & 8 \\
\hline 5 & Non - user friendly & 15 \\
\hline 6 & Difficuities in multi user capabilities & 14 \\
\hline 7 & $\begin{array}{c}\text { Requirement of specialized high processing } \\
\text { equipment }\end{array}$ & 1 \\
\hline 8 & $\begin{array}{l}\text { Limited Finance of the construction } \\
\text { organization }\end{array}$ & 5 \\
\hline 9 & Expensive training programs & 7 \\
\hline 10 & Lack of client's interests & 4 \\
\hline 11 & $\begin{array}{c}\text { Top management support of the construction } \\
\text { organization }\end{array}$ & 11 \\
\hline 12 & Inadequate marketing of the technology & 12 \\
\hline 13 & Lack of time to explore the technology & 10 \\
\hline 14 & Lack of awareness about the technology & 3 \\
\hline 15 & Existence of champions using the technology & 6 \\
\hline
\end{tabular}

Fig. 9. Ranked Factors according to their RII 
Fig. 9. shows the factors which are ranked from highest to lowest according to their RII. From the above performed analysis, it can be said that the top most preventing factors for the adoption of VR in construction projects are

1. Requirement of specialized high processing equipment

2. High investment in VR

3. Lack of awareness about the technology

4. Lack of client's interest

5. Limited finance of the construction organization

6. Existence of champions using the technology

7. Expensive training programs

\section{Possible Mitigation Measures}

To overcome these identified factors several mitigation measures are provided through a wide review of literatures. These measures are considered to be more of a shortterm solution to accept and accelerate the adoption of the VR technology in the construction industry. The measures are as follows:

1. Construction companies need to consider investing in new technology with high investment but for this to happen, researchers need to do a wide variety of research on the application and usefulness of the technology and the cost benefit analyses for this technology should be carried out as the companies is not willing to invest without the true cost $\&$ time saving benefits from the technology

2. Awareness activities like VR awareness programs, better branding and marketing of the technology should be considered to take the technology to the construction industries and professionals. And increased access to the expertise knowledge about the VR should be given to the professionals by the organizations

3. Industry perception about the technology is that it is primarily used for gaming purposes (J. M. Davila Delgado [8]). This perception in the organizations and between the professionals should be corrected and changed. For this awareness about the application and benefits of the technology in construction should be created among the professionals and organizations.

4. Also, the awareness about the use and benefits of VR in constructions among the client's should be created by conducting awareness programs, exhibiting the technologies at expos, impressing the clients with the benefits of VR. When the clients have the interest in adopting the technologies and include them in project costs, the organizations would also consider to adopt the technology. 
5. Mixing of VR technology with the traditional method can also be done to help the professionals to shift and learn slowly instead of sudden shifting from traditional methods to new technology.

6. By creating VR technology facilities by the organizations and universities in aiding the engineers and students may also accelerate the adoption of the technology.

7. The role of ICT organizations also plays important role in adoption of the VR technology. They should provide more support in software, privacy and data ownership while using VR technologies and in reducing the prices of VR related hardware and software.

The above-mentioned measures are several possible solutions for adopting the VR technology in construction projects. By addressing these preventing factors and finding suitable mitigation solutions can help in adopting the VR technology in the construction projects and thus it may become a more common in the constructions like the BIM methods which paved its way from the traditional methods.

\section{CONCLUSION}

This study presents the factors that are preventing the adoption of virtual reality in construction projects. The objective of this study was to (i) identify the factors and find the most affecting factors that are preventing the adoption, (ii) to suggest possible mitigation measures to overcome the factors that are preventing the adoption of the technology. 15 factors were identified through a wide review of literature survey and was analysed through statistical methods and ranked between them. Several possible mitigation measures were suggested to overcome those identified factors through literature survey. Virtual reality is an emerging technology new in the field of constructions in the recent years. Organizations, professionals and researchers should make efforts to learn about the technology and increase the possibilities of adopting the new technology in the construction projects. When the factors which are preventing the adoption are addressed, the research and development gaps in the technology are mitigated VR may become more common in the construction field in the future years.

\section{REFERENCES}

1. Aukstakalnis, S., \& Blatner, D. (1992). Silicon Mirage: The Art and Science of Virtual Reality.

2. Davila Delgado, J.M., Oyedele, L., Demian, P., and Beach, T. (2020). Augmented and Virtual Reality in Construction: Drivers and Limitations for Industry Adoption: 
Journal of Construction Engineering and Management, Vol. 146, No. 7, p. 04020079, DOI: 10.1061/(ASCE)CO.1943-7862.0001844

3. Davila Delgado, J.M., Oyedele, L., Demian, P., and Beach, T. (2020). A research agenda for augmented and virtual reality in architecture, engineering and construction: Advanced Engineering Informatics, Vol. 45, No. May, p. 101122, DOI: 10.1016/j.aei.2020.101122

4. Fernandes, K.J., Raja, V., White, A., and Tsinopoulos, C.D. (2006). Adoption of virtual reality within construction processes: A factor analysis approach: Technovation, Vol. 26, No. 1, pp. 111-120, DOI: 10.1016/j.technovation.2004.07.013

5. Ghobadi, M., and M.E. Sepasgozar, S. (2020). An Investigation of Virtual Reality Technology Adoption in the Construction Industry: Smart Cities and Construction Technologies, pp. 1-35, DOI: 10.5772/intechopen.91351.

6. Jishtu, P., and A Yadav, M. (2020). Application of Augmented Reality \& Virtual Reality in Architecture and Planning: an Overview: pp. 67-79, DOI: 10.5121/csit.2020.102008.

7. Noghabaei, M., Heydarian, A., Balali, V., and Han, K. (2020). Trend analysis on adoption of virtual and augmented reality in the architecture, engineering, and construction industry: Data, Vol. 5, No. 1, DOI: 10.3390/data5010026.

8. Thabet, W ., Shiratuddin , M . F . \& Bowman, D . (2002), Virtual Reality in Construction, Engineering Computational Technology, Saxe-Coburg Publications, pg . 25 - 52 (Chapter Contributor), Saxe-Coburg Publications, 2002: ISBN 1-874672-172

9. Woksepp, S. (2007). Virtual Reality in Construction Tools, Methods and Processes: Construction Innovation, p. 191.

10. Wolfartsberger, J. (2019). Analyzing the potential of Virtual Reality for engineering design review: Automation in Construction, Vol. 104, No. November 2018, pp. 2737, DOI: 10.1016/j.autcon.2019.03.018. 